\title{
Nurturing Distributed Leadership Environments in Schools: Creative Strategies for Increasing Community Engagement and Energizing School Turnaround Efforts
}

\author{
Joseph Claudet \\ Department of Educational Psychology and Leadership, Texas Tech University, Lubbock, TX, USA \\ Email: joe.claudet@ttu.edu
}

Received 23 March 2014; revised 23 April 2014; accepted 10 May 2014

Copyright (C) 2014 by author and Scientific Research Publishing Inc.

This work is licensed under the Creative Commons Attribution International License (CC BY).

http://creativecommons.org/licenses/by/4.0/

c) (i) Open Access

\begin{abstract}
This article highlights multiple ways in which kindergarten through twelfth grade (K-12) school leaders can work collaboratively with education stakeholders in elementary and secondary school settings to develop distributed leadership environments in their school communities to address the persistent and often seemingly intractable teaching and learning improvement dilemma challenges that plague many schools today. Insights gleaned from a brief examination of the distributed leadership attributes of one communal cultural tradition are utilized as the basis for generating some creative strategies for nurturing distributed leadership environments in school settings. These strategies may be useful to elementary and secondary school leaders working in a variety of educational environments who are interested in broadening their collaborative teaming and instructional support networks and energizing their school turnaround and improvement efforts.
\end{abstract}

\section{Keywords}

Distributed Leadership Environments, Collaborative Teaming, Community Engagement, School Turnarounds

\section{Introduction}

As an organizational psychologist and school improvement consultant for K-12 schools and school districts for over two decades, I have spent a great deal of time working with large groups of teachers, campus administra- 
tors, district central office program directors, school board members, educational support agencies, and community stakeholders (parents, business leaders, etc.) who are often struggling with "organizationally entrenched" and intractable school improvement dilemma challenges in their school and district communities (e.g., dealing with student dropouts; providing supportive "multicultural sensitive" teaching and learning environments and resources for ever-increasing numbers of diverse students, many of whom are "English as a Second Language" (ESL) learners; finding funding to develop and maintain needed instructional programs and personnel; addressing a variety of complex community involvement issues, etc.). A recurring theme resonating through the efforts of all of these groups of education stakeholders in various school community contexts is the challenge of finding creative ways to energize community engagement in their schools and districts to build a critical mass of stakeholder support for needed school improvement initiatives.

Often, the most daunting school turnaround leadership challenges school leaders have to confront on their campuses are persistent, long-term dilemma challenges that have been festering for a number of years in their school and district communities as a result of entrenched educator and community stakeholder beliefs about teaching, students' learning potential, the limitations of traditional schooling, etc., as well as because of lax and/or insufficiently funded school improvement practices. These educational stakeholder beliefs can become significant roadblocks or barriers to enacting meaningful organizational and cultural change in schools-particularly for school leaders focused on trying to work collaboratively with education stakeholder colleagues to create, nurture, and sustain high-quality distributed leadership environments in their school communities to address their substantive learning improvement dilemma challenges. These kinds of pervasive, system-wide dilemma challenges plaguing today's elementary and secondary school communities are well known to K-12 school leaders, and can include perplexing leadership and decision making challenges such as: 1) standing behind and supporting the really good teachers in your school in the face of district demands to get immediate learning improvement results; 2) making difficult choices on allocating limited resources to various school programs; 3) doing what is really "best for each and every child" when funded programs often do not provide the needed resources to make doing this a practical reality; 4) executing "Reduction-In-Force" (RIF) administrative decisions to reduce or eliminate programs and/or personnel because of budget constraints; 5) providing professional learning and development support to individual teachers or teacher teams who may have fallen into a "rut" in terms of their individual or group professional learning development; 6) motivating teachers who have not yet stepped up to the plate to truly integrate technology into the curriculum and into the fabric of classroom teaching and learning (for these teachers, technology is still just an "add on”); and 7) providing instructional supervisory support and remediation opportunities to teachers who are using outmoded or ineffective methods of instruction. In addition to these kinds of "within school" or micro-organizational teaching and learning dilemma challenges, school leaders—-from a wider macro-organizational "whole school community" perspective—are often also similarly beset with a number of larger multi-stakeholder involvement and collaborative teaming challenges as well, including such difficult leadership tasks as: 1) confronting poor or nonexistent parental involvement; 2) dealing with schools that have "atrophied" as learning communities; 3) leading and enabling large contingents of school community members (teachers, campus administrators, parents, business and community members) to engage in genuine shared decision making, when the decision making structure in place in your school and/or district is really a bureaucratic façade; 4) realizing that your school community does indeed have diverse multicultural student populations, but does not yet have in place the "multicultural curriculum" and "multicultural learning assessments" necessary to be genuinely culturally responsive to those student populations; and 5) leading diverse groups of school community stakeholders to develop shared understandings and mutual respect (i.e., shared organizational vision) around a set of teaching, leading, and learning core values that will provide them with the necessary foundation to be able to develop creative sets of short- and long-term collaborative action strategies to dynamically move their school community forward. In light of these kinds of entrenched and system-wide challenges that school leaders routinely find themselves struggling with in their school communities, school and district community leaders (teachers, campus principals and assistant principals, instructional coaches, school counselors, district-level curriculum program coordinators and administrators, superintendents, parents, elected school board officials, and community members) are often left in a quandary on how to work together effectively as school improvement "collaborative teams" to identify and implement creative school turnaround strategies in their school campuses and districts to provide new learning opportunities for students.

The predictable failure of top-down, mandated change initiatives has been well documented in the literature on school reform (Sarason, 1993). Moreover, it has been shown that "reform" initiatives, in and of themselves, 
are pre-programmed to fail because they seek to "impose” change on educators and school stakeholders without expending the necessary time and effort to obtain genuine "buy-in" from these stakeholders on the practical purposes and payoffs of the reforms themselves. In fact, a good deal of the reform initiative efforts that many district and school administrators attempt are often, in reality, not "reform" initiatives at all, but are closer to being little more than "conform and comply" initiatives. Forced conformity and compliance ends up being the reality in many instances because the organizational and administrative leaders in these contexts (superintendents, central office program directors, campus principals and assistant principals, etc.) simply have not taken the time and expended the effort to nurture genuine "buy-in" from teachers, parents, and other education community members in mindfully embracing the teaching reform and learning improvement "ideas". Rather than seeking to "reform" schools with imposed new structures, it has become increasingly clear in the past decade that the only way to achieve meaningful and sustainable change in schools is through engaging in the systemic (and long-term) process of organizational “reculturing” (Fullan, 1993, 1999, 2001). And, importantly, engaging in deep, system-wide organizational reculturing requires that school change agent leaders work collaboratively at the ground level with large numbers of educators and school community stakeholders to get these educators and stakeholders to adapt and internalize the change ideas-including embracing and taking ownership in the purposes and payoffs of the change initiatives as they see them for themselves and the larger school community. Through doing this, education stakeholders will be able to change their "mindsets" to adopt and adapt the change ideas and effectively make them their own. The compelling reason for the critical importance of deepstructural organizational "reculturing" (as opposed to surface-level organizational "reforming") to ensuring the success of school turnaround efforts is clear: you need teachers' and other stakeholders' collective energy, enthusiasm, buy-in, and long-term commitment to make the change initiatives "stick" and become self-sustaining. Reculturing is the only way to ensure that meaningful change will "take hold" in a school organization. Reculturing is also the only way to generate robust and self-sustaining community-wide stakeholder engagement in school change and improvement initiatives. That is why "reculturing" always trumps "restructuring”. And that is why over the past two decades I have continuously championed the strategy of encouraging teachers, principals, counselors, and school community education partners at individual school campuses to come together to clarify and rally around their collective core values and beliefs about teaching and learning improvement, and to then leverage these core values and beliefs as the impetus to engage in ground-level, campus-based interventions to achieve meaningful learning improvement gains for students. The kinds of interventions that can really work in schools are those which directly immerse teachers, administrators, parents, and community members in the indepth analysis of classroom, instructional team, and school-level teaching and learning performance data as a means to develop targeted teaching and learning intervention efforts that focus in very specific ways on making practical, demonstrable gains in student learning performance with small, doable student learning improvement intervention programs. These intervention programs, many of which are very clearly defined (i.e., small-scale and manageable) "learning improvement projects" that collaborative school instructional teams design and implement together in their school communities, focus on leveraging teachers’ own classroom- and grade-level data as a primary impetus for designing creative "student learning improvement interventions" to address very focused and specific student learning improvement "need areas".

For school turnaround efforts in elementary and secondary schools to be genuinely effective, education stakeholders (teachers, principals, assistant principals, campus- and district-based instructional support personnel, parents, and community members) in these schools must learn how to work collaboratively and synergistically to engage in focused, ongoing data mining and analysis, and then be able to creatively leverage the results of these data analyses to inform their instructional decision making. Most importantly, this data analysis and instructional decision-making process must ultimately result in the generation of realistic school improvement plans and implementation strategies that can directly address students' diverse instructional support needs and enhance their overall learning performance. One important key to developing effective school turnaround and improvement strategies involves understanding the fundamental nature of collaborative work in teaching, leading, and learning organizations. I have found that examining the collaborative work practices of various communal cultures through a socio-cultural lens can provide a wide range of insights on how groups of people in various settings approach and navigate difficult micro- and macro-organizational challenges within their environmental contexts-including how these communal groups go about the process of refining and optimizing their collaborative teaming practices - and, in doing so, develop their own distinctive sets of creative strategies for effectively dealing with and overcoming these challenges. One communal culture, in particular, that has 
evolved some intriguing distributed leadership skills in response to the unique challenges of their environmental context is the Acadian communal culture of southwest Louisiana.

\section{Insights on Nurturing Distributed Leadership Environments from a Communal Cultural Tradition}

The French Acadians (Les Acadiens de France) of southwest Louisiana are a hardy people who over several centuries have utilized well their strong communal group mores in combination with their well-developed abilities for working synergistically with the natural environment to forge flourishing, family-centered communities resonating with a vibrant community-oriented culture. Originally part of large French settlements in Nova Scotia in the early 1700s, the French Acadians were evicted en masse from their Nova Scotia settlements in 1755 by the British (Marshall, 2005). As the prospect of all-out war between Britain and France in the region was imminent at the time, the British overseers in Nova Scotia resorted to this drastic step of evicting the French Acadians to prevent the Acadian people from allying with the French forces. The Acadians were forced to board ships with their few worldly possessions and sail south in search of a new homeland. Enduring harsh conditions and exhibiting unflagging determination, the Acadians sailed down the length of the North American Atlantic seaboard, navigated around the Florida peninsula, and crossed the Gulf of Mexico to eventually settle anew in the sprawling Mississippi river delta region of southwest Louisiana. The thick, overgrown vegetation and semi-tropical climate of the marshes and swamps of southwest Louisiana-starkly different from the environment they had become accustomed to in Nova Scotia-presented the Acadian people with a new and immensely challenging natural environment in which to build a new way of life.

The Acadians fused their strong desire for self-preservation as a people with a natural inclination toward collaboration to develop some unique cultural practices of their own to survive —and ultimately flourish —in their new environment. An especially interesting cultural practice that the Acadians engaged in early on was that of handfishing. The need for survival demanded that the Acadians learn how to creatively leverage the natural resources of the marshy environments in which they had newly settled to obtain sufficient food to support their communal group. Handfishing provided the Acadian people with a way to engage directly with the natural environment. The Acadians would wade into the bayous and tributaries of the lower Mississippi delta and forage around with their bare hands to catch catfish, turtles, and whatever other edible water-based food they could find. Refining their own handfishing methods from techniques probably gleaned from indigenous Indian tribes in the region, these Acadian fishermen utilized their rapidly developing knowledge of the marshland habitats in their newly adopted environment to catch fish swimming under logs and wash-out areas in waste-deep water in the accessible muddy bayous. The Acadians would then cook their fish catches on the banks of the bayous and distribute the freshly prepared food to the various families of their communal group. These handfishing activities were decidedly "community events" in which multiple individuals assumed various group-centered roles in support of the overall task at hand. While several members of the community working in small groups of two and three would handfish in the waterways, other community members would form "ad hoc groups" on the bayou banks to clean the fresh fish that were caught. Other groups would collect firewood and take on the various cooking tasks. Still other groups would work to ensure that the food that was caught and prepared would be distributed equitably to all families participating in the communal handfishing enterprise. Within all of these group tasks, veteran members who were highly proficient in the specific tasks at hand would work side by side with younger community members who would learn the essential techniques from their older, more experienced "coaches". These practices of "distributing handfishing tasks widely" throughout the whole communal group and engaging in ongoing "multi-generational coaching" reflected the Acadians' own strong cultural propensities for collaborative teaming as they sought to leverage the resources of their natural environment to support and sustain their communities. Moreover, as the Acadians continued to develop and refine their handfishing and other communal living efforts over time, these collaborative teaming practices-engaged in initially as a means to ensure their own survival-continued to be instrumental in helping the Acadians eventually flourish in their new environment.

Even today the Acadian people of southwest Louisiana continue to actively preserve and celebrate their rich cultural history through engaging regularly in the practice of handfishing. And, as in past generations, the present Acadians approach handfishing as an opportunity to express and nurture their rich communal way of life (Mire, 1990). In many Acadian towns dotting the southwest Louisiana bayou region, the practice of handfishing is still very widespread, with a typical Acadian handfishing weekend event involving a wide mixture of commu- 
nity members reflecting all aspects of community life—e.g., store owners, farmers, shopkeepers, barbers, dentists, bankers, and their entire families. This makes for a rich potpourri of participant diversity. As a central feature of handfishing activities, community members relinquish their regular weekday community roles and take on one or more "communal roles" of importance to the success of the handfishing event. Moreover, throughout the day-long handfishing event Acadians will often engage enthusiastically in active "role swapping" to best serve the multiple tasks at hand and the overall needs of the group. As a result, there is an infectious joie de vivre and camaraderie that is palpable and defines every Acadian handfishing event: some community members do the actual handfishing in the bayou, while others take on equally essential roles of cleaning the catfish and other edible fish that are caught, chopping firewood and stoking fires, and preparing the necessary ingredients to cook the fresh catch. The Acadians' collaborative bent also flows over into vibrant scenes of group music making and informal storytelling - all of which further enliven the handfishing communal festivities. Importantly, these kinds of communally distributed cultural activities (the music making, the storytelling, and the cooking and preparing of food) all serve as important multi-generational communication bridges in Acadian culture connecting the older, experienced generations with the younger generations. As such, these activities-always engaged in with others in an intensive, collaborative teaming atmosphere-help to blend together the beliefs, tastes, and perspectives of multiple generations, as well as serving an important cultural stewardship function as living cultural heritage vehicles for passing on the Acadian people's centuries-old cultural traditions. These cultural traditions include a strong sense of communal responsibility for protecting and preserving the natural environment (including finding creative ways to adapt synergistically to this environment), a commitment to active collaborative teaming to maximize community-wide learning and sharing, and the importance of working for the common good.

\section{Discussion}

The above example of the rich communal handfishing practices associated with the Acadian way of life serve to highlight three distinctive "distributed leadership attributes" of this communal culture: 1) an emphasis on combining an engrained cultural propensity toward collaborative teaming with a strong inclination toward exploring and learning from the natural environment; 2) a practical ingenuity in using and leveraging available tools and resources; and 3) a focus on real-world problem solving to ensure the survival and prosperity of the entire community. These distributed leadership attributes further reflect a set of deeply embedded "core communal values" that undergird the Acadians' social practices and bind the Acadians together in a close-knit and highly interactive (and productive) learning community. These core communal values include strong, shared beliefs in the importance of: 1) learning across generations (the group's mores and community values, in fact, serve as integral and integrative "cultural structures" for multi-generational social bonding and relationship-building); 2) constructing and "framing" collaborative inquiry as shared total immersion experiences; 3) encouraging and rewarding daring, flamboyant creativity; and 4) emphasizing continuous communal learning as a means to enhance the long-term survival and sustainability of the whole cultural community.

Intriguingly, these leadership attributes and core values—and the "Acadian" communal way of life they reflect-provide a basis for generating some very practical, real-world collaborative partnering strategies which school leaders in elementary and secondary campus settings can employ to nurture positive, organization-enhancing "distributed leadership environments" in their school communities. Nurturing these distributed leadership environments can be an important step toward establishing a positive, collaborative leading and learning school culture- a culture that can energize school leaders' collective school turnaround efforts and support school community members as they work together to realize demonstrable teaching, leading, and learning improvements in their school communities.

The sections below provide some specific examples of practical, collaborative partnering strategies that school leaders can employ in their school settings to increase community member engagement and energize school turnaround efforts.

\subsection{Utilizing School Data and Collaborative Teaming to Achieve Meaningful Learning Improvement}

Elementary and secondary school principals can enhance the prospects for success of their school turnaround efforts by working to maximize the number and kinds of opportunities available to personnel to become in- 
volved in the day-to-day leadership work of the school organization-and to become genuinely motivated to want to take active ownership in that leadership work. When principals work conscientiously to motivate educators to become actively involved in practical ways in the day-to-day leadership of their school through creating a variety of collaborative leadership roles for teachers to take on and make their own, teachers will begin to feel like they are being offered new opportunities to assume greater responsibility for the overall success of their school. Through involvement in these leadership roles, teachers will begin to embrace an active ownership in their school's leadership for learning improvement work and, as a result, will begin to think more seriously as organizational leaders about their school's data —and about how to utilize these data. Doing this helps educators nurture a solid distributive leadership capacity throughout their school organization.

As an integral part of their day-to-day professional work, teachers should be actively involved in collaboratively scrutinizing, discussing, and leveraging their own classroom- and grade-level data to improve and enhance instruction. Getting large numbers of educators actively engaged in mining and analyzing their own school data is the key to school turnaround success-the more "eyes and minds" school leaders have viewing and reflecting on their school's learning performance data the better. School leaders should encourage all educators in their school to proactively scrutinize and reflect on their school's teaching and learning data to generate as many multiple interpretations of that data as possible. School learning performance data-and educators' multiple interpretations of that data-provide the keys to unlocking educators' own teaching and learning improvement creative strategizing potential in any school context. Teachers and other school-based educators (principals and assistant principals, school counselors, school psychologists, diagnosticians, instructional support personnel, etc.) can engage in meaningful school data review and reflection both as individuals and by working together in collaborative groups within grade-level and academic teams, campus-wide improvement counsels, etc. Doing this will ensure that instructional teams in the school will have at their disposal as many creative ideas as possible to generate sensible action strategies to enhance teaching and learning effectiveness.

School leaders can set the stage for school turnaround success by working proactively to nurture a collaborative professional learning culture in their school communities that emphasizes the importance of teachers actively and continuously engaging with their own school data. This professional learning culture should encourage and be supportive of teachers in their ongoing efforts to analyze their own classroom- and grade-level student performance data. Importantly, this professional learning culture should serve as a school-based "organizational learning structure" within which teachers feel supported and empowered to engage in ongoing collaborative teaming efforts to utilize insights gleaned from their data analyses as the basis for designing and implementing data-specific learning interventions that target identified learning improvement goals. This process of leveraging real-world data as the basis for designing and implementing data-specific learning interventions to achieve clearly identified "improvement goals" can and should become an integral part of teachers' day-to-day professional teaching practice. Moreover, collaborative teams of educators working systematically together can reap substantial teaching and learning improvement gains through engaging in conscious efforts to drill down into their data to analyze and pinpoint underlying "root causes" of students' learning problems. Interestingly, teachers do not always take the time and make the conscious efforts needed to systematically engage in careful probing and analysis of their own teaching and learning performance data. As a result, these underlying root causes of many students' "learning difficulties" (which are often not readily apparent through a surface-level analysis) often go undetected in schools.

For example, teachers in a middle school setting serving a highly diverse seventh and eighth grade student population (with a $43 \%$ overall Hispanic student enrollment) may be finding that their classroom- and gradelevel data are revealing that seventh and eighth grade students' math learning is below state and district accountability levels because of students' poor performance on state tests. On the surface, it may appear to teachers that the "reason" for their grade-level (and school-level) student math learning difficulties could be traced directly to the fact that there are several new teachers at the school who have not yet completed all of the district's curriculum implementation trainings and who, therefore, are not yet utilizing and implementing the district curriculum properly. However, after examining their data much more closely (i.e., drilling down deeper into their data and looking for additional "clues" that can help these teachers identify hard-to-pinpoint learning difficulty "root causes"), teachers at this middle school begin to uncover additional evidence that suggests a much larger (and more systemic) cause of their students' math learning difficulties. Teachers begin to find evidence in their individual grade-level benchmark testing and progress monitoring data that strongly suggests that seventh and eighth grade Hispanic students at this middle school are under-performing particularly in the area of "math word 
problems”. Upon carefully examining and reflecting on all the additional evidence they have uncovered as a result of their "drill down" data analyses, teachers at this middle school begin to realize that a more logical and data-supported "root causal explanation" for why many of their multicultural Hispanic students are not achieving at their potential is because the instructional methods and materials that the teachers are currently using do not meet these students' specific multicultural learning needs. Many of these Hispanic students, in fact, are having difficulty comprehending and culturally relating to the unfamiliar contextual descriptions included in many of the math word problems. Through engaging in this process of drilling down and digging deeper into their data to identify learning difficulty "root causes", these teachers now realize that the appropriate learning improvement strategy they should take is to work together to design a number of specific instructional accommodations to better address all of their students' math learning needs. These instructional accommodations could include: 1) developing more diversified and multi-culturally sensitive sets of word problems and incorporating these word problem sets into seventh and eighth grade math teaching materials; 2) engaging in more intensive collaborative peer teaching efforts to develop and integrate multicultural instructional strategies such as individual studentintensive reading level screening, diagnostic assessment, and reading coaching directly into daily math classroom teaching and learning practices; and 3) implementing an aggressive student progress monitoring program that includes multiple learning remediation opportunities so students are provided the individualized learning support they need to stay on track. These combined instructional accommodation strategies-developed as a result of teachers' conscious collaborative efforts in drilling down deep into their own student learning performance data to uncover underlying "root causes" of student learning difficulties-hold considerable promise as positive instructional strategies that could more effectively address students' overall learning needs on their campus.

Importantly, in connection with the above school-based "data mining and collaborative teaming" example, developing a "school-wide vision for learning improvement" mindset, along with the collaborative leader skills to be able to work effectively with teacher teams to conceptually and operationally "link" classroom- and gradelevel data analyses to practical efforts to attain larger school-wide "learning performance goals" for students, is a critical school turnaround leadership capacity that principals need to develop-both in themselves and in their educator colleagues - to be able to effect positive teaching and learning improvements in struggling schools. Moreover, this school-wide vision for learning improvement mindset, rather than being "static" and "unchanging”, should continuously evolve within a school community as school leaders (teachers, administrators, students, and parents) discover and refine creative ways to work together effectively to implement data-supported instructional programs that have the power to enhance the learning performance of all students.

\subsection{Leveraging Available Tools and Resources to Expand School Community-Wide Learning Opportunities}

In communal cultural practices emphasizing rich group learning and sharing experiences, such as in the French Acadian cultural practice of handfishing, individuals engage in multiple communal activities together and actively participate in "role swapping" and "inter-generational peer coaching and sharing" of practical knowledge and skills that enhance the learning of the entire group. These cultural practices serve as important multi-generational cultural communication bridges connecting older, more experienced community members with the younger generations coming up. Today, individuals in education settings can leverage the connecting power of available digital mobile technologies and social media tools to further expand the impact of this kind of multigenerational peer coaching and sharing on their daily teaching and learning practices. These digital tools themselves - very much in the same way the centuries-old Acadian cultural practices served as "communication bridges" to enhance group learning - become a new $21^{\text {st }}$ century kind of multi-generational communication bridge uniting the accumulated knowledge and wisdom of experienced master educators with new generations of teachers, instructional specialists, and learning support personnel and providing new possibilities for reinventing (and dramatically expanding) classroom teaching and learning.

For example, educators in many schools today are exploring the possibility of implementing "flipped instruction" designs to reenergize their classroom teaching and create new learning opportunities for students. Flipped instruction designs present an array of exciting new teaching and learning opportunities for educators and students as they creatively change and expand the traditional interactive dynamics of classroom teaching and learning (Khan, 2012). In traditional classrooms teachers typically present new content knowledge to students utilizing lectures and direct instruction delivery methods supported by available information presentation tools (e.g., 
powerpoint slides, visuals, etc.). This traditional classroom teaching and learning model essentially involves students in: 1) passively absorbing new content knowledge during teacher-led classroom presentations; and then 2) working on their own to actually apply this new content knowledge in isolation at home as they complete lesson assignments. The flipped instruction model essentially reverses this arrangement through emphasizing the critical importance to students' learning success of the teacher-student interactive instructional guidance and content knowledge application dimensions of the overall teaching and learning process. In the flipped instruction model teachers develop video-on-demand ("vodcasts") and audio-on-demand ("podcasts") presentations of instructional material which they upload to a classroom or course website. Students are then able to download these digital lesson materials for viewing and reviewing at home. In this "flipped" instructional model the main focus of classroom activities then shifts to utilizing classroom time for intensive teacher-to-student instructional guidance and support as students work to "apply" content knowledge they have viewed and reviewed in the digital vodcasts and podcasts directly to lesson assignments. The flipped instruction model offers multiple opportunities for both new and veteran teachers to dynamically expand and deepen students' grasp of core content knowledge through leveraging limited classroom time and newly available "digital creation tools" (audio- and video-on-demand development software) and "digital communication and learning tools" (mobile technologies such as laptops, ipads, ipods, and the like; and the world-wide web) to focus squarely on students' content knowledge application and practical problem solving skill development.

Of course, one critical key to school turnaround leadership success in moving forward with instructional technology integration initiatives such as the flipped instruction model is getting veteran teachers on board the instructional initiative bandwagon. Veteran teachers, in general, are typically "digital immigrants" rather than "digital natives" - these teachers have engaged in much of their professional teaching practice before the advent and widespread educational use of digital technologies and the world-wide web (Prensky, 2010). Because of this, many veteran teachers simply do not have the familiarity and level of proficiency with digital technologies and social media they need in order to be able to confidently begin to integrate these digital tools effectively into their daily teaching practices. In fact, many veteran teachers often articulate very legitimate "lack of time and training" concerns when faced with the challenge of learning how to implement various new technology-integrated instructional methods. As a result, many veteran teachers feel substantial anxiety at the prospect of engaging in technology integration initiatives, primarily due to their feelings of lack of confidence in their own applied instructional technology skills. Thus, it is important to provide veteran teachers with both the "ideas" and the "essential tools and skills" they need to empower them to be able to participate comfortably and effectively in any new campus-based and/or district-mandated technology-integrated instructional change initiatives. So, a very specific instructional leadership goal of principals in schools implementing instructional technology integration initiatives should always be to work to develop clear understandings among veteran teachers of the real purposes and payoffs of technology-integrated instruction. Doing so will help significantly toward building teachers' mental buy-in and ownership in these kinds of initiatives - which is critical to achieving implementation success.

To address head-on this challenge of building "teacher buy-in" the principal can often work to identify one or more technology-proficient teachers at the school who would be willing to provide technology-integrated instructional modeling and one-on-one technology training support to other teachers in their own classrooms. These technology-proficient teachers could model the flipped classroom instruction development process at the campus for several weeks, including the steps involved in preparing and recording audio and video lessons (podcasts, vodcasts, etc.), as well as how to upload these digital files to the school's website and/or how to directly email these lessons to students. Additionally, these technology-proficient teachers could invite other teachers in their school to observe their own flipped classroom teaching, including these technology-proficient teachers' specific content application and instructional support interactions with students during class time. As a follow-up to these teacher modeling and one-on-one training support efforts, the principal could then arrange multiple school-wide teacher collaborative sharing meetings at the school so teachers engaging in the flipped classroom instruction "modeling" and "one-on-one training" activities could collectively share their instructional implementation and ongoing student progress monitoring data with fellow teachers and respond to teacher questions. Importantly, this technology-integrated instructional modeling and training should also be complemented by ongoing, data-informed open conversations among all teachers at the school regarding how utilizing technology-integrated instructional techniques in their classroom teaching can reap positive instructional benefits for 
both teachers and students. In particular, these conversations can highlight the multiple teaching and learning benefits that can be derived through integrating digital technologies into teachers' classroom practices, including: 1) creating new digital ways for teachers to engage in collaborative instructional planning for technology-integrated teaching; 2) expanding teachers' professional toolbox for designing student progress monitoring and individual remediation programs; and 3) enabling teachers to analyze and leverage their classroom- and gradelevel student performance data in more comprehensive ways to inform teachers' team-centered instructional decision making to positively impact students' overall learning success.

There are a variety of creative community involvement strategies that school leaders can utilize to enhance the overall implementation effectiveness and long-term sustainability of their technology-integrated instructional improvement efforts (such as implementing flipped instruction models). For example, in any given school community support area it may be possible to find some parents and/or small business professionals with digital mobile technology and social media communication expertise who would be willing to provide some assistance with technology training and support needs for teachers needing help with developing technology-integrated lessons (e.g., audio/video recording of lessons, etc.). In addition, the school principal might be able to identify one or more other schools in the region (who have already had some success in implementing the flipped instruction model at their campuses) who would be willing to serve as "collaborative partner campuses" to share the creative strategies and insights they have gleaned through their own flipped instruction implementation efforts. School administrators and teachers might also conduct visitations to some of these partner campuses to observe first-hand these educators' implementation designs and instructional best practices. It also might be possible for the school to connect with a regional university college of education to identify faculty who have an interest in technology-integrated instructional designs (such as flipped instruction) and who might be willing to provide technical assistance and training support to teachers at the school. School leaders can also take advantage of available "rollover technology funds" from their school district as they work to develop and refine longterm instructional technology integration goals and implementation plans for their campuses. Most importantly, school principals can actively encourage and support teachers in a number of interrelated "hands-on" digital instructional integration activities, including: 1) incorporating new technology components (such as flipped instruction) into their lesson plans on a regular reporting period basis; 2) requiring teachers to participate in communication and technology professional development offerings; and 3) involving teachers in regular instructional team meetings to brainstorm and share ideas and solicit feedback to build open communication networks regarding the purposes and payoffs of technology integration. Encouraging teachers to engage in these kinds of ongoing professional learning and sharing activities will pave the way toward nurturing teachers' full support and ownership in technology integration initiatives.

Indeed, as the above flipped instruction example suggests, educators in schools today have before them a wide array of powerful new tools in the form of digital mobile technologies (including laptops, ipads, ipods, and the like) and widely accessible social media resources (e.g., facebook, twitter, pinterest, LinkedIn, blogs, wikis, social bookmarking, shared annotation services, RSS readers) to essentially reinvent their own staff development and professional learning. Teachers can considerably expand the effectiveness of their classroom teaching practices through taking on new professional development challenges, such as collaboratively learning about audio-on-demand (podcasting) and video-on-demand (vodcasting) instructional delivery, and how to develop digital "streaming video" flipped classroom lessons to better meet the $21^{\text {st }}$ century diverse learning needs of today's students. Moreover, teachers can share their own digital integration professional learning experiences and insights in real time with colleagues both in their own and other school districts through regular interactive postings on facebook, pinterest, and other collaborative sharing sites and through showcasing their instructional teams' professional learning best practices on school and district websites. These "teacher-initiated" digital coaching and sharing activities that teachers engage in will serve over time to help create flourishing $e$-learning communication networks among educators across many different schools and school districts-networks that will have the capacity to greatly facilitate and accelerate teaching and learning improvements for a wide array of diverse learners. Most importantly, these digital tools and the new kinds of multi-dimensional, informal communication and interactive sharing opportunities they present to teachers, instructional support personnel, and administrators in schools and school districts can serve to empower educators to develop new levels of ownership in their own continuous learning — and, as a result, enhance the overall quality of teaching and learning in their classrooms. 


\subsection{Focus on Real-World Problem Solving to Energize Instructional Improvement Efforts}

Educators in today's K-12 school environments must address a complex array of student learning and school improvement challenges. Teachers, instructional support personnel, and administrators working in these settings can significantly enhance their effectiveness in addressing their school's improvement challenges through adopting a data-driven, real-world problem solving approach to student learning improvement. Such a real-world problem solving approach requires teachers and administrators to engage directly in analyzing their own school teaching and learning data to identify specific learning improvement "need areas". These identified need areas can then provide the necessary "focus" for developing targeted student learning intervention projects to address students' learning deficiencies - projects which, when implemented effectively, have the potential to yield demonstrable student learning improvement results. It is important to note here that these kinds of data-driven school turnaround and learning intervention efforts at elementary and secondary campuses can be significantly energized through encouraging a variety of school community stakeholders to become immersed and actively involved in these targeted learning intervention projects focused on achieving realistic student learning improvement goals. Forward-moving schools thrive on "school-community partnerships" as a way to include many kinds of education stakeholders and community partners directly in ongoing school improvement efforts. The creative idea here is to leverage school-community partnership building as a means to dynamically expand collaborative instructional teaming to energize school-wide student learning improvement.

In school communities where school leaders have internalized a robust school turnaround leadership mentality, teacher grade-level and interdisciplinary teams (at the elementary, middle, and secondary levels) are continually working to mine and analyze their own classroom- and grade-level student performance data to identify areas of low student performance. These low student learning performance indicators could appear in any one or more of a number of specific content areas, such as reading and language arts, writing, social studies, etc., or in one or more STEM (i.e., science, technology, engineering, and math) disciplines. These student learning performance indicators present campus-based school leaders (teachers, instructional team leaders, department chairs, principals, assistant principals, school counselors, etc.) with excellent opportunities to utilize these data to engage proactively in data-informed, problem-driven instructional analysis as a means to brainstorm and identify creative intervention program designs to improve students' learning effectiveness. Educators can utilize multi-level data mining and analysis techniques to work together in their grade-level and interdisciplinary teams to carefully review student benchmark and progress monitoring data and "drill down" into these data fields to identify very specific learning improvement "need areas". Teams of educators can then begin to work collaboratively to brainstorm creative learning intervention program designs that directly target these identified student improvement need areas. Once these learning intervention program designs are fully developed they can then be incorporated into various "learning improvement grant proposals" which individual campuses (working through their district central offices) can submit to a variety of local and regional funding agencies (e.g., private foundations, regional businesses, corporate sponsors, etc.) to obtain funding support for intervention program implementation.

For example, one instructional challenge that educators currently face in many school contexts is how to creatively address the learning needs of "English as a Second Language" (or, ESL) learners (note: ESL learners are also frequently described by educational specialists as being "English Language Learners" [ELL] and "emergent bilingual learners"). The core challenge in responding effectively to the learning needs of these ESL students is developing creative immersive learning experiences for these students to assist them in developing their oral and written English language applied communication skills. One creative strategy that has proven effective in many school contexts is to design and implement learning intervention projects utilizing the concept of Literature Learning Circles. Teacher planning teams can utilize the Literature Learning Circle concept to design a variety of interactive learning projects that incorporate several student-customized instructional design features to address the unique language learning needs of ESL learners, as well as to address the learning needs of the school's general population of English Language Arts (ELA) students. Literature Learning Circle projects involve students directly in "immersive collaborative learning" through group reading and active peer sharing and discussion of reading content. Students' overall language skill development is enhanced through the multiple opportunities provided within Literature Learning Circle activities for peer modeling of oral and written language communication skills and positive language acquisition reinforcement. In addition, a variety of individuals (parents, business leaders, community volunteers, etc.) from the larger school community can be invited to 
participate in the Literature Learning Circle projects as “adult mentors”. These adult mentors can serve as important role models for English Language Arts learners in terms of assisting these students in acquiring essential real-world oral and written communication skills, as well as providing these students with the career-readiness information and mentoring support structures they will need to be able to compete effectively in their future career choices.

Interestingly, ESL students are often less involved in school co-curricular activities (such as after-school sports, music groups, etc.) because they are needed to assist their parents in everyday family activities (e.g., helping with home chores, babysitting younger siblings, serving as a translator during parents' business and medical appointments, etc.). Because of this, many principals today face the added (and daunting) challenge of effectively needing to reinvent their school's entire organizational and instructional leadership culture to be more inclusive and supportive of their school community's widening spectrum of culturally diverse learners. This "reinvented" school culture must be one that is able to motivate not only the school's teachers to become actively involved in the ongoing work of building supportive school-to-home partnerships, but must also inspire ESL parents, community members, and the students themselves to adopt a more proactive, engaged, and inclusive learning success mentality. This learning success mentality can be nurtured throughout the school-wide community environment through the positive reinforcement efforts of multiple educational community constituents (school leaders, parents, business leaders, community members, etc.) — who all have a substantial stake in properly nurturing and supporting the long-term learning achievement of present ESL students, as well as future generations of ESL learners. In order to bring about this school culture transformation, many school leaders are employing a number of creative strategies that extend beyond the traditional school curricular and co-curricular program offerings. These strategies often include having teachers and school counselors visit ESL students and their parents in their homes to develop "school-to-home instructional support networks" that can more directly address these students' specific learning and social adjustment needs. Moreover, in some schools these teacher home visits evolve into fully developed "school-to-home liaison programs" that provide a wide range of health and social support services to students and their families-either provided directly by school personnel (e.g., school nurse/student health director; school psychologist, etc.) or through connecting these students and their families with local and regional social service agencies. Other strategies that can be utilized by principals seeking to reinvent their school's instructional leadership culture include such things as exploring creative ways to increase parents' direct involvement in the school teaching and learning environment through: 1) inviting parents to give talks on their cultural traditions and experiences to students; 2) staging a variety of school-community cultural awareness events at the campus; 3) encouraging parents to serve as "parent mentors” to students; etc.

Teachers in today's school environments are well aware of the importance of making language arts (and other content) learning appealing to $21^{\text {st }}$ century learners, including giving students multiple opportunities to access teacher-developed digital oral and written language communication lessons from home. Teachers seek to accomplish this through employing a variety of $21^{\text {st }}$ century digital teaching and learning tools (such as iBooks, iTunes University, and the like) and through implementing multiple versions of flipped instruction designs. Thus, a foundational premise of many fundable program ideas and program curricular designs is that all students need to learn how to access and utilize technology-enabled, digital instructional content to optimize their learning. Because of this, in terms of the creative dimensions of an overall "language learning improvement" intervention project, teachers in elementary and secondary school settings could consider as part of their intervention project's curricular design involving the students directly in hands-on learning through creating their own "Literature Learning Circles” website. Students could continuously develop and refine this website as part of their involvement in the "Literature Learning Circles" project implementation design. Elementary and secondary school students today are "digital natives" (they were born after the start of the internet age), so these students are naturally enthusiastic about using and learning creatively via any kind of digital and internet-enabled means (Prensky, 2010). Thus, one creative way to enhance students' learning engagement is through involving students directly in their own "Literature Learning Circles project website” creative development effort. Students can be supported in their project website development efforts with assistance provided by their classroom teachers, as well as perhaps with some website development technical support provided by area business mentors (e.g., mentors from local newspapers, radio/TV stations, area chambers of commerce, as well as other kinds of news organizations, large and small business entrepreneurs, etc.). My experiences over the years in assisting educators in schools and school districts with their project-based learning intervention efforts have revealed that many area business leaders are typically eager to offer their assistance to help mentor and immerse area elementary- and 
secondary-level students in using and leveraging real-world, $21^{\text {st }}$ century technology applications to enhance their language learning and communication skills development. This would also be a big "selling point" to potential grant proposal reviewers, who are always looking to see how a grant proposal incorporates creative ways to directly involve multiple community partners in the teaching and learning design of the proposal. Students participating in the Literature Learning Circles project could receive language arts learning instruction and mentoring guidance from both teachers and business community mentors who would work collaboratively within the project's intervention design to provide multiple immersive learning opportunities for students. Additionally, in some Literature Learning Circles project designs, students in one grade level might also be able to interact with and receive peer-mentoring feedback from students in "higher" grade levels. Within these immersive learning settings students could participate directly in peer-to-peer learning teams within which they could engage in multiple technology-mediated activities — such as threaded group discussions on their project website- to generate a variety of ideas and share their multiple perspectives on literature text readings. These group discussions would provide students with opportunities to conduct "collaborative peer analyses" of their own multiple viewpoints on text readings to discern commonalities and differences in their literature reflections, and then enable students to leverage these peer discussions to generate reflective group summaries of their multiperspectivist analyses. In addition, students could further develop and enhance their real-world applied "language learning and communication skills" through learning how to use simple available digital design tools (such as: iMovie, Prezi, Strip Designer, Comic Life, Slide Rocket, and the like) to develop multimedia digital content about their ongoing creative literature and language arts learning activities (including their text reading peer analyses and group discussions, their group-generated literature reading reflective summaries, etc.). Students participating in the project could then upload and link their newly developed multimedia digital content directly to their "Literature Learning Circles" program website. And, again, since elementary and middle schoolage students are definitely "digital natives" (they were born during the internet age), developing their own website showcasing their own "literature and language learning adventures" would really appeal to them. Importantly, this would help students acquire valuable " $21^{\text {st }}$ century digital content development and writing communication skills", which many business employers would consider to be very valuable job skill assets (as these kids grow up and begin to enter the job market).

When considering the implementation challenges associated with various student learning intervention project designs (such as the "Literature Learning Circles" language learning and communication skills development project described above), it should be noted that it is well known among staff development consultants and school improvement specialists that teachers rarely receive adequate training (i.e., up-to-date, content-specific, comprehensive, and useful professional development) on creative instructional strategies relating to how to teach and evaluate content area subjects-particularly in ways that appropriately support ESL students' learning effectiveness. To directly address this specific professional training and learning need area for teachers, educators working collaboratively in individual schools (teachers, department heads, instructional coaches, principals and assistant principals, counselors, etc.) can "turnkey" their intervention project or program designs further through providing targeted learning intervention project development modules on how to develop and implement "Literature Learning Circles" programs to other schools and districts (as well as, of course, to educators and education stakeholders within their own district). Doing this can create important new collaborative learning and professional sharing opportunities for administrators, teachers, and stakeholders in other school districts and regions of the state. Additionally, these school educators, working collaboratively as the intervention program designers, could develop these learning intervention project development modules so that they could be uploaded as a "professional learning website" onto the internet (along with some "ESL teaching 'applied learning proficiency instruction and evaluation' teacher resource materials" and even perhaps a few Youtube "how to get started videos"), so that administrators, teachers, and stakeholders in other schools and districts could access and learn from these modules. This would represent yet another level of digital turnkeying (i.e., "internet-enabled" collaborative learning and professional sharing among administrators, teachers, and stakeholders in other districts) that could become part of the school's overall "learning intervention program curriculum design". Importantly, doing this would be a way to initiate a potentially expanding "collaborative network" (or consortium) among multiple schools and districts who either have already developed or are interested in developing similar ESL learning enhancement programs for the purpose of sharing program ideas and techniques and business contacts (including regional businesses and "real-world learning support mentors" who may want to participate in the program, such as newspapers, radio and TV stations, area chambers of commerce, area businesses, 
etc.). This also could be a creative way to attract some businesses who might want to eventually provide grant monies of their own to support the continued sustainability of these kinds of "language learning and communication skills development” programs. And, reviewers of these kinds of learning intervention proposals would definitely be thinking along these lines. Reviewers always want to read program proposals that they feel show promise in terms of being able to become "self-sustaining on their own" through the ability of the proposal's program "idea" to attract further funding support. The key idea here is to include as many turnkeying opportunities as possible within the school's overall grant proposal design to maximize the potential to impact as many educational stakeholders as possible ("maximizing the bang for the funding agency bucks"). Grant proposal reviewers are always looking when reviewing proposal submissions for evidence that educators are thinking about the long-term expandability (multiple stakeholder impact) and self-sustainability of their learning intervention program ideas through developing as many kinds of multi-stakeholder communication and sharing networks as possible. Multiple stakeholder impact potential and long-term self-sustainability of the program idea are two important proposal design elements that proposal reviewers always look for in assessing the "fundability" of grant proposals.

Of course, the above learning intervention project ideas and associated grant proposal development strategies targeting the learning needs of English Language Arts (ELA) and English as a Second Language (ESL) students are only offered as one example among many possible fundable learning intervention projects that collaborative teams of educators could develop for their campuses. Educators in elementary and secondary schools can easily adapt the above ideas on how to engage in collaborative mining and analysis of their own classroom- and grade-level instructional data to identify learning improvement need areas as a creative springboard for designing a variety of targeted student learning improvement intervention programs within and across a number of content areas (including math, science, social studies, English/language arts/writing, music and fine arts, health and physical education, etc.) on their campuses. For example, educators working in high school settings can address both the content skills acquisition and career preparation needs of students through designing a variety of school-to-work programs as a means to provide interested students with real-world learning experiences in their own communities. These school-to-work programs could include such program designs as work-study entrepreneurial placement programs for senior high school students. In these work-study placement programs, senior high school students actually spend part of their weekly "school time" gaining real-world relevant training experiences and acquiring professional work skills in a local or regional business setting (such as a restaurant, retail outlet, garden supply store, community service enterprise, etc.) under the tutelage of an adult "business mentor". In these kinds of work-study entrepreneurial placement settings students receive intensive "professional skills coaching" from their business mentors. Students participating in these school-to-work programs benefit substantively from these programs' emphasis on directly involving students in highly immersive, on-the-job experiences. Moreover, students involved in these programs acquire professional communication, people interaction, and business ethics skills that can help prepare them in positive ways for future entrepreneurial and community service careers.

There is literally a wealth of creative program ideas and designs that educators in elementary and secondary school settings can consider as they work to provide real-world relevant, applied content learning improvement and enrichment opportunities for their students. These applied learning opportunities could include such campus-based programs as: 1) botanical and agricultural vegetable gardens; 2) school robotic teams; 3) pre-medicine clubs; 4) hands-on science clubs; etc. Importantly, these kinds of applied content learning programs can often create new and exciting opportunities for expanding school-community partnerships with civic leaders and entrepreneurs in a variety of local and regional businesses, civic agencies, and community service organizations-all of whom are stakeholders in the educational effectiveness of their community's schools. Through focusing on "school-community partnership building" as a creative means to substantively expand educators' collaborative instructional teaming practices in their schools, school leaders will be taking positive steps toward energizing their school's turnaround efforts through nurturing a robust distributed leadership culture that values multi-stakeholder, community-wide active engagement in supporting the learning success of all students.

\section{Conclusion}

In this article, I have briefly profiled some of the current, intractable teaching and learning improvement challenges confronting educational leaders in today's elementary and secondary schools. Importantly, I have sought 
to frame this profile in very specific ways in terms of the real opportunities educators have for addressing these multiple, daunting school turnaround and improvement challenges through nurturing robust distributed leadership environments in their school communities.

In particular, the article offers some specific examples of practical, collaborative partnering strategies that school leaders can employ to foster the development of positive distributed leadership environments in their schools - environments that have the capacity to support and invigorate the teaching, leading, and learning efforts of educators and community members as they work together to meet the needs of diverse learners. These partnering strategies involve educators and community members working together synergistically in: 1) utilizing their own instructional team and school-level data (and their ongoing collaborative teaming efforts in analyzing and generating action plans based on these data) to achieve meaningful learning improvement gains on their campuses; 2) leveraging available $21^{\text {st }}$ century tools and resources to reinvent and recharge their school learning improvement efforts; and 3) engaging in data-informed, real-world problem solving to design and implement targeted student learning improvement projects. These strategies can be adapted for use in various school community settings to increase community member engagement and revitalize educators' collective school improvement work. The creative strategies presented herein seek to contribute to the evolving literature on the potential of using distributed leadership techniques to positively impact teaching and learning improvement efforts in elementary and secondary schools (Spillane, 2006).

Importantly, attracting the long-term commitment and energies of a wide array of education stakeholders to nurture school-level distributed leadership environments can be an important step toward establishing a positive and self-sustaining collaborative instructional leadership culture in elementary and secondary school communities. Just as the Acadians leveraged the distinctive distributed leadership attributes of their own communal cultural heritage to ensure their own survival and create new opportunities for their communal groups to flourish in their new leading and learning environments, so too can school leaders tap into the distributed leadership potential of their own school communities to design and implement creative strategies to energize stakeholders' ongoing school turnaround efforts and support school community members as they work together to provide enhanced teaching and learning opportunities for all learners.

\section{References}

Fullan, M. (1993). Change Forces: Probing the Depths of Educational Reform. London: Falmer Press.

Fullan, M. (1999). Change Forces: The Sequel. Philadelphia: Falmer Press/Taylor \& Francis, Inc.

Fullan, M. (2001). The New Meaning of Educational Change (3rd ed.). New York: Teachers College Press.

Khan, S. (2012). The One World Schoolhouse: Education Reimagined. London: Hodder \& Stoughton Ltd.

http://dx.doi.org/10.4021/wjon578w

Marshall, B. (2005). France and the Americas: Culture, Politics, and History. Santa Barbara, CA: ABC-CLIO, Inc.

http://dx.doi.org/10.1353/tam.2005.0082

Mire, P. (1990). Anything I Catch: The Handfishing Story. Documentary Film. Lafayette, LA: Pat Mire Films.

Prensky, M. (2010). Teaching Digital Natives: Partnering for Real Learning. Thousand Oaks, CA: Corwin.

Sarason, S. B. (1993). The Predictable Failure of Educational Reform: Can We Change Course before It's Too Late. San Francisco: Jossey-Bass Publishers.

Spillane, J. P. (2006). Distributed Leadership. San Francisco: Jossey-Bass Publishers. 
Scientific Research Publishing (SCIRP) is one of the largest Open Access journal publishers. It is currently publishing more than 200 open access, online, peer-reviewed journals covering a wide range of academic disciplines. SCIRP serves the worldwide academic communities and contributes to the progress and application of science with its publication.

Other selected journals from SCIRP are listed as below. Submit your manuscript to us via either submit@scirp.org or Online Submission Portal.
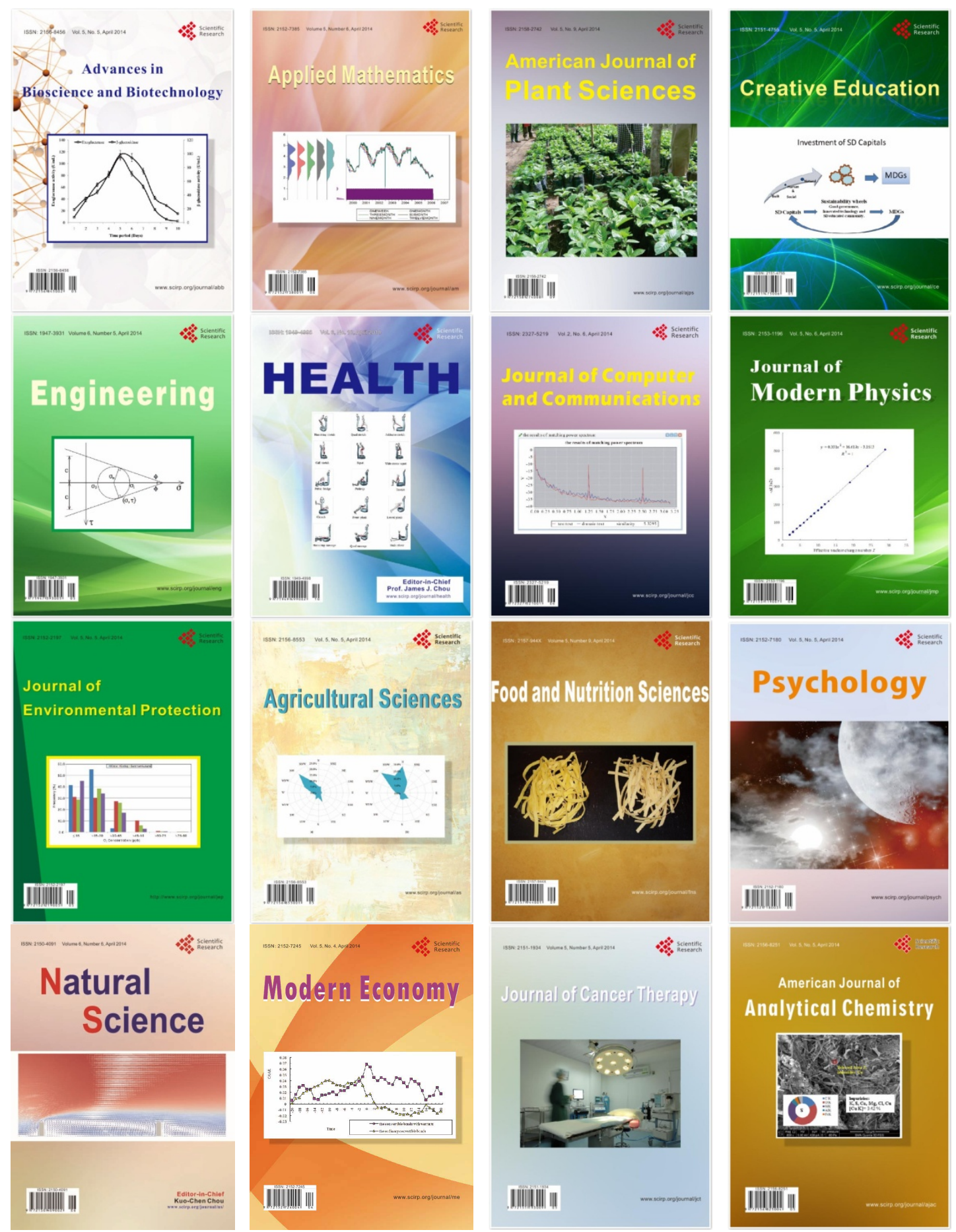